\title{
Evaluation of Cutting Parameters by Determination of the Grey Correlation Analysis Methods of the Effects on the Cutting Force and Surface Roughness of Duplex Stainless Steels (2205)
}

\author{
Ahmet MAVi
}

\begin{abstract}
In this study, the effects of coated (TiAlN and TiN) drills and cutting parameters on drilling performance were investigated. Drilling operations were carried out by drilling holes $20 \mathrm{~mm}$ deep with $5 \mathrm{~mm}$ diameter drills on duplex stainless steel (2205). Three different cutting speeds $(15,20$ and $25 \mathrm{~m} / \mathrm{min})$ and three different feed rates $(0.05,0.075$ and $0.1 \mathrm{~mm} / \mathrm{min})$ were used in the experiments. The effects of different drills and cutting parameters on the cutting force and surface roughness are measured. Experiments were made in full factorial and optimum conditions were determined for the values measured by the gray relational analysis method. According to the gray correlation analysis value, it was found that the feed rates on the cutting force and surface roughness had a greater effect than the other factors. In addition, variance analysis (ANOVA) was performed to determine the effects of cutting parameters on cutting force $(F c)$ and surface roughness $(R a)$. According to ANOVA results, it is determined that the most effective parameter on $\mathrm{Ra}$ is the feed rate and the most effective parameter on the second degree is the cutting speed.
\end{abstract}

Keywords: cutting force; drilling; duplex stainless steel (2205); gray relational analysis; surface roughness

\section{INTRODUCTION}

Duplex stainless steels which are a new type of stainless steels have become considerably significant in the last couple of years. Duplex stainless steels consisting of ferrite and austenite mean "consisting of two pieces" in Latin. Existence of austenite provides ductility and general corrosion resistance whereas ferrite provides mechanical strength and resistance to stress corrosion cracking. Small amounts of sulphur $(\mathrm{S})$ and phosphorous $(\mathrm{P})$ are added into material to get rid of thermal cracking that can be formed during solidification of the structure. Ferritic stainless steels have high stress corrosion resistance and austenitic steels have the ability of high ductility, toughness and welding. Duplex stainless steels have the characteristics of these two structures (ferritic + austenitic). Duplex stainless steels, due to their high mechanical properties, enable the usage of parts with thinner section [1]. Duplex stainless steels contain austenite and ferrite phases in equal amounts. They are now widely used in many fields due to their outstanding mechanical properties and corrosion resistance [2-3].

In general, stainless steels, because of their high hardness values, toughness and lower thermal conductivities, are among the hardly machined materials [4-8]. Another problem in the machining of stainless steels is due to fracture toughness; because of these, the tool/chip interface temperatures increase affecting the surface quality adversely. Furthermore, at high cutting speeds, piling (BUE) is observed on the cutting edges and this spoils the quality of machined surface and increases the cutting forces [9]. Duplex stainless steels, even if they have better mechanical properties, they are hardly machined compared to austenitic stainless steels. This is due to the high strength of the alloy [10].

In drilling processes, determination of suitable cutting conditions is an important point. Because of the increasing demands in the manufacturing sector, investigation of the parameters affecting the wearing and life of cutting tools has always been a subject of research and the main target was to reach the optimum machining conditions by decreasing the cost and increasing the performance [11]. To put forward the conditions with which the best results could be obtained, primarily the characteristic specifying the performance was determined and the factors affecting this characteristic were examined. Afterwards, tests were carried out to determine the effects of these factors on the characteristic specifying the performance and to find out the most suitable combination. In order to evaluate the effects and suitability of the machining parameters and factors, some techniques were developed to estimate the life of cutting tools before making tests. The most important advantages of these estimation techniques having experimental design, modelling and optimization are high accuracy, reliability and low cost. When the industrial conditions are considered, application of test design procedures is the most efficient approach to realize these tests most efficiently according to both economic conditions and time constraints and to commentate the results [12].

Grey system theory is an alternative and effective approach in cases of little or discrete information, much data and uncertainty. Grey theory is advised in cases which do not suit any distribution with multi variable statistics, have no sufficient data and which cannot be modelled due to uncertainty [13]. Grey relational analysis is getting widely used in literature as the decision making method. The applications of GRA in different fields give a better idea for the applicability of the method [14].

There are some studies investigating the machinability of duplex stainless steel alloys. Nomani et al., in their study, examined the effects on tool wear in the drilling of duplex stainless steels and austenitic stainless steels. In the study austenitic stainless steels gave better results [15]. Philip Selvaraj et al., in their study optimized the surface roughness, cutting forces and tool wear in the turning of duplex stainless steels with Taguchi method. In the study they determined that the effective parameter on surface roughness was feed rate and the most effective parameters on the main cutting forces were feed rate and cutting speed [16]. Paro et al., in their study, observed the tool wears created during drilling of duplex stainless steels with 
internal cooled tools. For this process they used two different duplex stainless steels (Duploks 27 and A890 1). As a result, both of the steels were subjected to BUE. A890 1A was subjected more than the other. During machining of A890 1A tool life was observed to be higher [17]. Carlborg used four duplex and one high-alloy austenitic steels to compare the performance of cementite carbide tools. They investigated the tool life and tool wear [18]. Grzegory et al., in their study examined the effects of cutting parameters on the tool life during machining of duplex stainless steels with coated and uncoated carbide tools and they observed that tool life decreased with the increasing cutting speed. It was also observed that coated tools gave better results from the point of life [19]. Braham-Bouchnak et al., examined the tool wear during machining of duplex stainless steels by cooling with high pressure water and obtained better surfaces in the high pressure machining compared to dry cutting. At the same time, tool life increased $20 \%$ with the pressurized cooling [20].

Researches on duplex stainless steels are limited in number. Besides, most of the studies are on turning and milling. In this study, the effect of cutting parameters on cutting forces and surface form characteristics during drilling of duplex stainless steels was investigated by using grey analysis method. Besides, ANOVA variance analysis was used to determine the most effective parameter.

\section{MATERIAL AND METHOD}

\subsection{Experimental Procedure}

In the study, duplex 2205 quality stainless steel was taken as the test material. Chemical compositions of the test material duplex 2205 quality stainless steel are given in Tab. 1. In the tests TiN and TiAlN coated carbide drills (Walter cutting tool company) with $5 \mathrm{~mm}$ diameter were used. The cutting forces and moment values were realized by using KISTLER 9272A dynamometer with 4 components. A multi-channel amplifier was used for transferring the signals coming from the dynamometer to the data reading card (KISTLER PCIM DAS 1602/16) and

finally KISTLER Dynoware 2825-A-02-01 software (compatible with Windows operating system) was employed to carry out the data processing and to obtain graphs. During processing, roughness values of hole surfaces were obtained by using portable Mahr Perthometer M1 type surface roughness measuring device, Figs. 1 and 2. In the drill ability tests three different feeds $(0.05,0.075$ and $0.1 \mathrm{~mm} / \mathrm{rev})$ and three different cutting speeds $(15,20$ and $25 \mathrm{~m} / \mathrm{min})$ were used. Tests were carried out at $20 \mathrm{~mm}$ depth by employing external cooling procedure. Tests were made by considering the catalogue values of the company (producing cutting tools with respect to ISO 3685) and using the values given in Tab. 2. In every test a new tip was used.

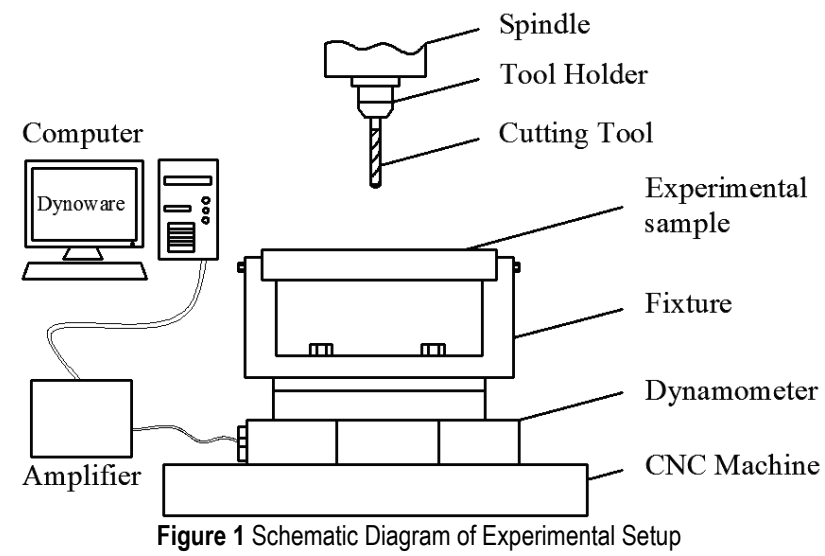

Table 1 Chemical composition of Duplex Stainless Steel (2205)

\begin{tabular}{|c|c|c|c|c|c|c|c|}
\hline $\mathrm{C}$ & $\mathrm{Mn}$ & $\mathrm{P}$ & $\mathrm{S}$ & $\mathrm{Si}$ & $\mathrm{Cr}$ & $\mathrm{Mo}$ & $\mathrm{Ni}$ \\
\hline 0.03 & 2.0 & 0.035 & 0.015 & 1.0 & $21-23$ & $2.5-3.5$ & $4.5-6.5$ \\
\hline
\end{tabular}

Table 2 Cutting parameters and their levels

\begin{tabular}{|c|c|c|c|c|}
\hline Symbol & Cutting Parameters & Level 1 & Level 2 & Level 3 \\
\hline$A$ & $\begin{array}{c}\text { Cutting tool coating } \\
\text { types }\end{array}$ & TiAlN & TiN & - \\
\hline$B$ & $\begin{array}{c}\text { Feed rate, } f \\
\mathrm{~mm} / \mathrm{rev}\end{array}$ & 0.05 & 0.75 & 0.1 \\
\hline$C$ & $\begin{array}{c}\text { Cutting speed, } V \\
\mathrm{~m} / \mathrm{min}\end{array}$ & 15 & 20 & 25 \\
\hline
\end{tabular}

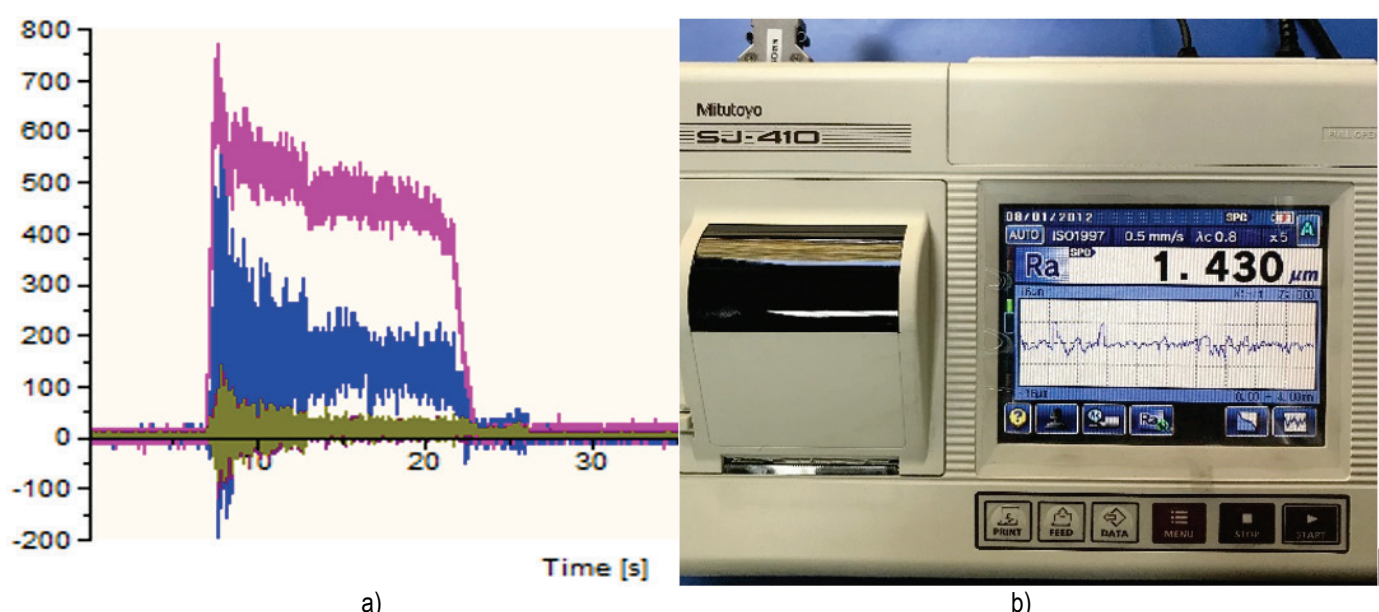

Figure 2 Measurements of Experimental Results. a) Cutting forces diagram; b) surface roughness

\subsection{Plan of Experiment Analysis}

In the last years Taguchi method is being used very often to increase the productivity in the research and development made for the production of high quality products with low cost. The parameter design of Taguchi is very important for a keen design. Taguchi method is a special procedure developed to examine all of the 
parameters that are planned to realize the tests with a limited number of tests [21-23]. For the application of Taguchi test plan 3-levelled two parameters and 2- levelled one parameter were used. Taguchi L18 orthogonal series was used to identify the degree of freedom condition necessary for the study. The parameters and their levels used in this series are given in Tab. 2. In the experimental studies the holes were drilled three times and averages were taken. Test design and corresponding test results are given in Tab. 3 .

Table 3 Experimental design using Taguchi L18 orthogonal array and experimental results.

\begin{tabular}{|c|c|c|c|c|c|}
\hline \multirow{2}{*}{$\begin{array}{c}\text { Experiment } \\
\text { number }\end{array}$} & \multicolumn{2}{|c|}{ Cutting Parameters } & \multicolumn{2}{c|}{ Experimental Result } \\
\cline { 2 - 6 } & $A$ & $B$ & $C$ & $R a / \mu \mathrm{m}$ & $F C / \mathrm{N}$ \\
\hline 1 & 1 & 1 & 1 & 1.21 & 496.42 \\
\hline 2 & 1 & 1 & 2 & 1.11 & 491.71 \\
\hline 3 & 1 & 1 & 3 & 0.97 & 486.33 \\
\hline 4 & 1 & 2 & 1 & 1.43 & 576.84 \\
\hline 5 & 1 & 2 & 2 & 1.17 & 519.39 \\
\hline 6 & 1 & 2 & 3 & 0.89 & 498.34 \\
\hline 7 & 1 & 3 & 1 & 1.69 & 758.09 \\
\hline 8 & 1 & 3 & 2 & 1.42 & 694.59 \\
\hline 9 & 1 & 3 & 3 & 0.99 & 714.05 \\
\hline 10 & 2 & 1 & 1 & 0.99 & 555.96 \\
\hline 11 & 2 & 1 & 2 & 0.76 & 515.77 \\
\hline 12 & 2 & 1 & 3 & 0.59 & 483.82 \\
\hline 13 & 2 & 2 & 1 & 1.17 & 663.14 \\
\hline 14 & 2 & 2 & 2 & 1.07 & 642.21 \\
\hline 15 & 2 & 2 & 3 & 0.82 & 624.06 \\
\hline 16 & 2 & 3 & 1 & 1.93 & 740.39 \\
\hline 17 & 2 & 3 & 2 & 1.67 & 664.07 \\
\hline 18 & 2 & 3 & 3 & 1.03 & 700.16 \\
\hline
\end{tabular}

\section{DETERMINATION OF MACHINING PARAMETERS 3.1 Grey Relational Analysis (GRA)}

The purpose of this study is to determine the optimum cutting parameters in drilling of the Dublex stainless steels with GRA method. The whole data was measured experimentally and was normalized in between $0-1$. The most important point in the normalization of factor series is the type of approach which is to be used. As an example if the points in the series are wanted to be bigger values, points having bigger values in the linear normalization get values close to "1" and points having small values will get values close to "0" [24-26]. Normalization of the test results can be made with the following three different approaches;

If "the lowest the best" is the case then the series is normalized in the following way:

$$
y_{i}(k)=\frac{\max x_{i}^{0}-x_{i}^{0}(k)}{\max x_{i}^{0}-\min x_{i}^{0}(k)}
$$

Here, $y_{i}(k)$ GRA normalizing value, the maximum value of $x_{i}^{0}(k)$ is $\max x_{i}^{0}(k)$, the minimum value is $\min x_{i}^{0}(k) \cdot x^{0}$ represents the optimum value. In the Grey relational analysis method, grey indicates the relational degree and relational degrees of eighteen series $\left(y_{0}(k)\right.$ and $\left.y_{i}(k), i=1,2, \ldots, 18 ; k=1,2,3\right)$ are determined. Grey relational coefficient $\xi_{i}(k)$ is calculated according to the equation 2-5 given below:

$$
\begin{aligned}
& \xi_{i}(k)=\frac{\Delta_{\min }+\varsigma \Delta_{\max }}{\Delta_{0 i}(k)+\varsigma \Delta_{\max }} \\
& \Delta_{0 i(k)}=\left\|y_{0}(k)-y_{i}(k)\right\|
\end{aligned}
$$

$\Delta_{\max }=\max _{\forall j \in i} \max _{\forall \in k}\left\|y_{0}(k)-y_{i}(k)\right\|$

$\Delta_{\min }=\min _{\forall j \in i} \min _{\forall \in k}\left\|y_{0}(k)-y_{i}(k)\right\|$

Here, $\Delta_{0 i}(k)$ is the absolute deviation value between $y_{0}(k)$ and $y_{i}(k) \zeta=$ distinguishing coefficient $\left(0 \_1\right) ; \Delta_{\min }$ is the minimum value of $\Delta_{0 i}, \Delta_{\max }$ is the maximum value. Grey relational degree $\left(Y_{i}\right)$ is obtained by taking the average of grey relational coefficients and is stated as follows:

$$
\Upsilon_{i}=\frac{1}{n} \sum_{k=1}^{n} \xi_{i}(k)
$$

Here $n$ is the grey relational coefficient number obtained from the normalized test results. The High Gray association level indicates a strong association between $y_{0}(k)$ and $y_{i}(k)$. If the two series in comparison have the same values, grey relational degree is 1 . Grey relational degree specifies how close the comparison series value is to the reference series value.

Sequences for the absolute deviation values calculated corresponding to normalized values, calculated grey

\begin{tabular}{|c|c|c|c|c|c|c|}
\hline \multirow{2}{*}{$\begin{array}{l}\text { Experiment } \\
\text { number }\end{array}$} & \multicolumn{2}{|c|}{ Calculated absolute deviation values } & \multicolumn{2}{|c|}{ Calculated gray relational coefficient } & \multirow{2}{*}{ Grey relational grade } & \multirow{2}{*}{ Order } \\
\hline & $R a / \mu \mathrm{m}$ & $F_{c} / \mathrm{N}$ & Measured $\mathrm{Ra} / \mu \mathrm{m}$ & Measured $F_{c} / \mathrm{N}$ & & \\
\hline 1 & 0.537313 & 0.95406 & 0.51938 & 0.915851 & 0.718 & 6 \\
\hline 2 & 0.61194 & 0.971233 & 0.563025 & 0.945596 & 0.754 & 5 \\
\hline 3 & 0.716418 & 0.990848 & 0.638095 & 0.982026 & 0.810 & 2 \\
\hline 4 & 0.373134 & 0.660845 & 0.443709 & 0.595838 & 0.520 & 11 \\
\hline 5 & 0.567164 & 0.87031 & 0.536 & 0.794042 & 0.665 & 7 \\
\hline 6 & 0.776119 & 0.947059 & 0.690722 & 0.904256 & 0.797 & 4 \\
\hline 7 & 0.179104 & 0 & 0.378531 & 0.333333 & 0.356 & 17 \\
\hline 8 & 0.380597 & 0.231524 & 0.446667 & 0.394174 & 0.420 & 15 \\
\hline 9 & 0.701493 & 0.160572 & 0.626168 & 0.373294 & 0.500 & 12 \\
\hline 10 & 0.701493 & 0.736975 & 0.626168 & 0.655286 & 0.641 & 8 \\
\hline 11 & 0.873134 & 0.883509 & 0.797619 & 0.811042 & 0.804 & 3 \\
\hline 12 & 1 & 1 & 1 & 1 & 1.000 & 1 \\
\hline 13 & 0.567164 & 0.346192 & 0.536 & 0.433348 & 0.485 & 14 \\
\hline
\end{tabular}
relational coefficient and grey relational degree and 18 compatibility series are given in Tab. 4 and Fig. 3.

Table 4 The sequences after data preprocessing, the calculated Grey relational coefficient and Grey relational grade for 18 comparability sequences 
Table 4 The sequences after data preprocessing, the calculated Grey relational coefficient and Grey relational grade for 18 comparability sequences (continuation)

\begin{tabular}{|c|c|c|c|c|c|c|}
\hline \multirow{2}{*}{$\begin{array}{l}\text { Experiment } \\
\text { number }\end{array}$} & \multicolumn{2}{|c|}{ Calculated absolute deviation values } & \multicolumn{2}{|c|}{ Calculated gray relational coefficient } & \multirow{2}{*}{ Grey relational grade } & \multirow{2}{*}{ Order } \\
\hline & $R a / \mu \mathrm{m}$ & $F_{C} / \mathrm{N}$ & Measured $R a / \mu \mathrm{m}$ & Measured $F_{c} / \mathrm{N}$ & & \\
\hline 14 & 0.641791 & 0.422503 & 0.582609 & 0.464039 & 0.523 & 10 \\
\hline 15 & 0.828358 & 0.488679 & 0.744444 & 0.494403 & 0.619 & 9 \\
\hline 16 & 0 & 0.064535 & 0.333333 & 0.348319 & 0.341 & 18 \\
\hline 17 & 0.19403 & 0.342801 & 0.382857 & 0.432078 & 0.407 & 16 \\
\hline 18 & 0.671642 & 0.211215 & 0.603604 & 0.387962 & 0.496 & 13 \\
\hline
\end{tabular}

\subsection{Analysis of Variance (ANOVA)}

Variance Analysis (ANOVA) is one of the analysis methods used in investigating the effect of different parameters on the result. ANOVA provides the determination of the percentage contribution value of parameters affecting the output value. Percentage contribution $(P C R)$ is calculated as follows:

$P C R=\left(\frac{S S_{A}-\left(V_{e}\right) \cdot\left(\vartheta_{a}\right)}{S S_{T}}\right) \times 100$

Here $S S_{A}$, Sum of squares for parameter $A ; V_{e}$, error variance; $S S_{T}$, sum of squares; $\vartheta_{a}$, the degrees of freedom for parameters $A$ and $S S_{T}$.

In addition to $P C R, F$-test can be used to analyses the effects of performance parameters. In general, the parameter with a high $F$ value must have a great effect on the performance. An evaluation based on both $P C R$ and $F$ test can be used to determine the most effective test parameter.

\subsection{Analysis of Experimental Results}

\subsubsection{Grey Relational Analysis of Cutting Force and Surface Roughness}

According to L18 experimental design results, surface roughness and main cutting force values are wanted to be lower. For this reason "the lowest-the best" sequence normalization approach was used. Absolute deviation values which were calculated against the normalized values of all of the measurement results and calculated grey relational analysis results are given in Tab. 4. For all of the tests, grey relational coefficients and then grey relational degrees were obtained. When the coefficients were found out, the distinguishing coefficient was taken as $\varsigma=0.5$. From Tab. 4 and Fig. 3 it is clearly seen that the lowest grey relational degree was obtained in the test no 12 .

\begin{tabular}{|c|c|c|c|c|c|}
\hline \multirow{2}{*}{ Symbol } & \multirow{2}{*}{ Parameter 5 Response table for machining parameters } \\
\cline { 3 - 6 } & & \multicolumn{2}{|c|}{ Average grey relational grade by factor level } \\
\hline$A$ & Tool & $0.6156^{*}$ & 0.5907 & & 0.025 \\
\hline$B$ & Feed rate & $0.7878^{*}$ & 0.6016 & 0.4200 & 0.368 \\
\hline$C$ & $\begin{array}{c}\text { Cutting } \\
\text { speed }\end{array}$ & 0.5099 & 0.5958 & $0.7037^{*}$ & 0.194 \\
\hline
\end{tabular}

First of all, for each parameter the same level values were summed and then their averages were taken and this way mean grey relational degree was obtained for that parameter. This process was repeated for each parameter in the second and third levels and the reaction table was obtained for grey relational degrees. As a result of the evaluation with respect to ("the lowest-the best") the results in Tab. 5 and Fig. 4 were obtained. According to Tab. 5, $A 1 B 1 C 3$ was determined as the optimum parameter. It is seen that the best result is $A 1$; in the TiAlN coated tool, $B 1$; at the $0.05 \mathrm{~mm} / \mathrm{rev}$ feed rate and $C 3$; at $25 \mathrm{~m} / \mathrm{min}$ cutting speed.

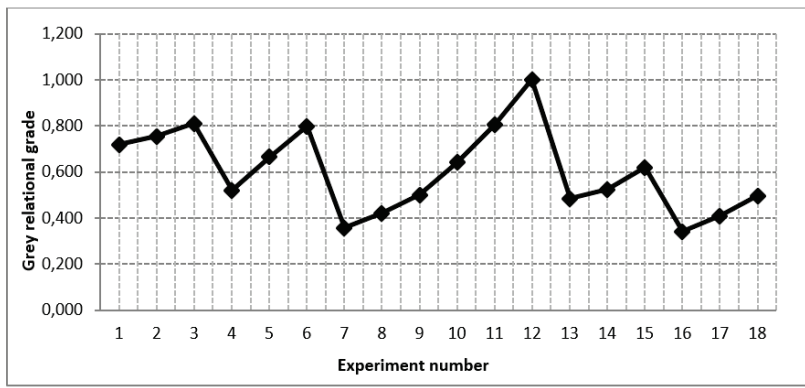

Figure 3 Grey relational grade graphic

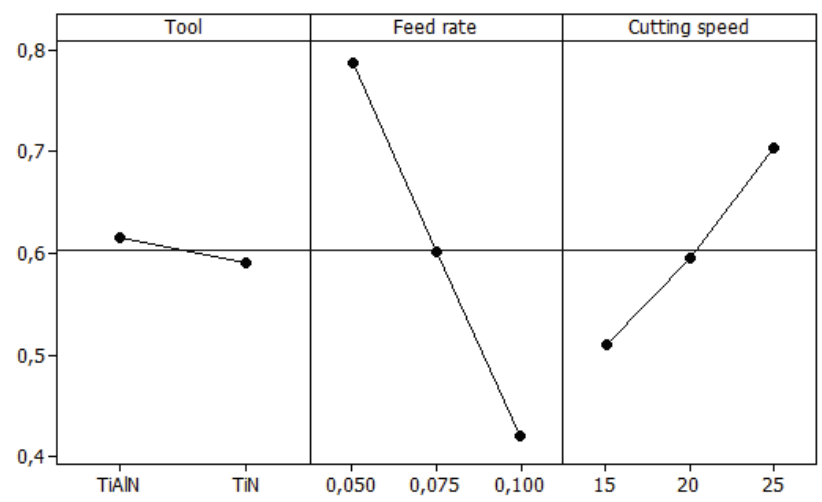

Figure 4 Impact ratings: Cutting tool, feed rate $(f)$ and cutting speed $(V c)$

\subsubsection{Analysis of variance (ANOVA)}

One of the analysis methods used in the investigation of the effect of different parameters on the result is analysis of variance (ANOVA). The percentage contributions of the parameters affecting ANOVA output values are given in Tab. 6.

In Tab. 6 effect degrees of the parameters affecting the cutting force and surface roughness were determined. The effect degrees of each parameter were obtained by using variance analysis (ANOVA). The most effective parameter affecting the cutting force and surface roughness came out to be feed rate with $69.62 \%$.

\subsubsection{Confirmation Test}

From the studies made (by the aid of Taguchi) according to "the lowest-the best" equation, $A 1 B 1 C 3$ were found out as the optimum cutting parameters depending on the obtained GRA degrees. Verification tests were carried out with respect to these parameters. Verification tests were made three times and the averages were taken. In the end, the starting and estimated GRA results in Tab. 7 were obtained. 
From Tab. 7 it is seen that verification test results found out according to the test results (depending on the starting parameters) were improved by $53 \%$ on average.

Table 6 ANOVA for grey relational grade (GRG)

\begin{tabular}{|c|c|c|c|c|c|c|}
\hline Source & $d f$ & $S S$ & $M S$ & $F$-test & $p$-coefficient & $P C R / \%$ \\
\hline$A$ & 1 & 0.002783 & 0.002783 & 0.68 & 0.427 \\
\hline$B$ & 2 & 0.405883 & 0.202941 & 49.36 & 0 \\
\hline$C$ & 2 & 0.113188 & 0.056594 & 13.76 & 0.001 \\
\hline Error & 12 & 0.049342 & 0.004112 & & 18.38 \\
\hline Total & 17 & 0.571196 & & & & \\
\hline
\end{tabular}

Table 7 Results of confirmation experiment

\begin{tabular}{|c|c|c|c|}
\hline & Initial cutting parameters & Prediction & \multicolumn{2}{|c|}{ Optimal cutting parameters } \\
\cline { 3 - 4 } & & $A 1 B 1 C 3$ & \\
\hline Level & $A 2 B 2 C 2$ & & 1.04 \\
\hline$R a$ & 1.07 & & 497.78 \\
\hline$F C$ & 642.21 & 0.900860 & 0.753 \\
\hline$G R G$ & 0.490 & & \\
\hline
\end{tabular}

The improvement in $G R G=0.263$

The percentage improvement in $G R G=53 \%$

\section{CONCLUSIONS}

The effects of cutting parameters on surface roughness and cutting forces in the drilling of duplex stainless steels were investigated and the results obtained with this study are summarized below:

- According to ANOVA results, the most significant factor in affecting the surface roughness and cutting force was the feed rate having a percentage contribution of $69.62 \%$.

- The confirmation experiments were performed to verify the optimal cutting parameters. The improvement of $G R G$ from the initial cutting parameters to the optimal cutting parameters was percentage improvement in $G R G=53 \%$

- The optimum parameters for the maximum surface roughness and cutting force were computed by using the Grey Relation Analysis (GRA). The optimum parameters for surface roughness and cutting force efficiencies were obtained as $A 1 B 1 C 3$.

- The confirmation results have indicated a good agreement between experimental and predicted results within the ranges of the applied parameters.

\section{REFERENCES}

[1] Ciofu, F., Nioata, A., \& Dobrota, D. (2010). Welds in the Duplex Stainless Steel. Fascicle of Management and Technological Engineering, 19, 52-59.

[2] Badji, R., Bouabdallah, M., Bacroix, B., Kahloun, C., Bettahar, K., \& Kherrouba, N. (2008). Effect of Solution Treatment Temperature on the Precipitation Kinetic of $\sigma$ Phase in 2205 Duplex Stainless Steel Welds. Materials Science and Engineering, 496(1-2), 447-454. https://doi.org/10.1016/j.msea.2008.06.024

[3] Nowacki, J. \& Lukojc, A. (2005). Structure and Properties of the Heat-Affected Zone of Duplex Steels Welded Joints. Journal of Materials Processing Technology, 164-165, 1074-1081. https://doi.org/10.1016/j.jmatprotec.2005.02.243

[4] Dolinsek, S. (2003). Work hardening in the drilling of austenitic stainless steels. Journal of Materials Processing Technology, 133(1-2), 63-70. https://doi.org/10.1016/S0924-0136(02)00245-5

[5] Jiang, L., Paro, J., Häinninen, H., Kauppinen, V., \& Oraskari, R. (1996). Comparison of grindability of HIPped austenitic 16L, duplex 2205 and super duplex 2507 and ascast 304 stainless steels using alumina wheels. Journal of Materials Processing Technology, 62(1-3), 1-9. https://doi.org/10.1016/0924-0136(95)02199-X

[6] O'Sullivan, D. \& Cotterell, M. (2002). Machinability of austenitic stainless steel SS303. Journal of Materials Processing Technology, 124(1-2), 153-159. https://doi.org/10.1016/S0924-0136(02)00197-8

[7] Paro, J., Hänninen, H., \& Kauppinen, V. (2001). Tool wear and machinability of HIPedP/M and conventional cast duplex stainless steels. Wear, 249(3-4), 279-284. https://doi.org/10.1016/S0043-1648(01)00570-1

[8] Shao, H., Liu, L., \& Qu, H.L. (2007). Machinability study on $3 \% \mathrm{Co}-12 \% \mathrm{Cr}$ stainless steeling milling. Wear, 263(1-6), 736-744. https://doi.org/10.1016/j.wear.2007.01.074

[9] Ciftci, I. (2006). Machining of austenitic stainless steels using CVD multi-layer coated cemented carbide tools. Tribology International, 39(6), 565-569. https://doi.org/10.1016/j.triboint.2005.05.005

[10] Voronenko, B. (1997). Austenitic-ferritic stainless steels: a state of the art review. Metal Science and Heat Treatment, 39(10), 428-437. https://doi.org/10.1007/BF02484228

[11] Rajmohan, T., Palanikumar, K., \& Prakash, S. (2013). Greyfuzzy algorithm to optimize machining parameters in drilling of hybrid metal matrix composites. Composites: Part B, 50, 297-308. https://doi.org/10.1016/j.compositesb.2013.02.030

[12] Krishnamoorthy, A., Boopathy, R. S., Palanikumar, K., \& Davim, J. P. (2012). Application of grey fuzzy logic for the optimization of drilling parameters for CFRP composites with multiple performance characteristics. Measurement, 45, 1286-1296. https://doi.org/10.1016/j.measurement.2012.01.008

[13] Feng, C. M. \& Wang, R. T. (2000). Performance evaluation for airlines including the consideration of financial ratios. Journal of Air Transport Management, 6, 133-142. https://doi.org/10.1016/S0969-6997(00)00003-X

[14] Huang, J. T. \& Liao, Y. S. (2003). Optimization of machining parameters of wire-edm based on grey relational analysis and statistical analysis. International Journal of Production Research, 41, 1707-1720. https://doi.org/10.1080/1352816031000074973

[15] Nomani, J., Pramanik, A., Hilditch, T., \& Littlefair, G. (2013). Machinability studyof first generation duplex (2205), second generation duplex (2507) and austenite stainless steel during drilling process. Wear, 304, 20-28. https://doi.org/10.1016/j.wear.2013.04.008

[16] Selvaraj, D. P., Chandramohan, P., \& Mohanraj, M. (2014). Optimization of surface roughness, cutting force and tool wearof nitrogen alloyed duplex stainless steel in a dry 
turning process using Taguchi method. Measurement, 49, 205-215. https://doi.org/10.1016/j.measurement.2013.11.037

[17] Paro, J., Hänninen, H., \& Kauppinen, V. (2001). Tool wear and machinability of HIPed P/M and conventional cast duplex stainless steels. Wear, 249, 279-284. https://doi.org/10.1016/S0043-1648(01)00570-1

[18] Carlborg, C. (1991). Machinability of duplex stainless steel. Proceedings of Duplex Stainless Steel, 1(1), 683-696.

[19] Królczyk, G., Gajek, M., \& Legutko, S. (2013). Effect ofthe Cutting Parameters Impact on Tool Life in Duplex Stainless Steel Turning Process. Tehnički vjesnik, 20(4), 587-592.

[20] Braham-Bouchnak, T., Germain, G., Robert, P., \& Lebrun, J. L. (2010). High Pressure Water Jet Assisted Machining Of Duplex Steel: Machinability And Tool Life. International Journal of Material Forming, 3(1), 507-510. https://doi.org/10.1007/s12289-010-0818-9

[21] Gopalsamy, B. M., Mondal, B., \& Ghosh, S. (2009). Taguchi method and ANOVA: An approach for process parameter optimization of hard machining while machining hardened steel. Journal of scientific and Industrial research, 68, 686.

[22] Selvaraj, P. D. \& Chandramohan, P. (2010). Optimization of surface roughness of AISI 304 austenitic stainless steel in dry turning operation using Taguchi Design method. Journal of Engineering Science and Technology 5, 293-301.

[23] Ross, P. J. (1998). Taguchi techniques for quality engineering. McGraw-Hill.: New York.

[24] Aghaie, A.Z., Rahimi, A.B., \& Akbarzadeh, A. (2015). A general optimized geometry of angled ribs for enhancing the thermo-hydraulic behavior of a solar air heater channel - a Taguchi approach, Renew. Energy, 83, 47-54 https://doi.org/10.1016/j.renene.2015.04.016

[25] Günes, S., Manay, E., Senyigit, E., \& Özceyhan, V. (2011) A Taguchi approach for optimization of design parameters in a tube with coiled wire inserts. Appl. Therm. Eng., 31(1415), 2568-2577. https://doi.org/10.1016/j.applthermaleng.2011.04.022

[26] Acır, A., Canlı, M. E., Ata, I., \& Çakıroglu, R. (2017). Parametrik optimization of energy and exergy analyses of a novel solar air heater with grey relational analysis. Applied Thermal Engineering, 122, 330-338.

https://doi.org/10.1016/j.applthermaleng.2017.05.018

\section{Contact information:}

\section{Ahmet MAVi, PhD}

Gazi University, OSTIM Vocational College,

Department of Mechatronics, Ankara, Turkey (06500)

E-mail: amavi@gazi.edu.tr 